Universidad de Guadalajara

DERECHO GLOBAL. ESTUDIOS SOBRE DERECHO Y JUSTICIA

Año 2021, Vol. VII. Número 19, Noviembre 2021-Febrero 2022, ISSN: 2448-5128 e-ISSN: 2448-5136

https://DOI.org/ 10.32870/dgedj.v6i19.436

ROSALÍA QUIROZ PAPA DE GARCÍA

Universidad Nacional Mayor de San Marcos rquirozp@unmsm.edu.pe

CESAR H. LIMAYMANTA ÁLVAREZ

Universidad Nacional Mayor de San Marcos

climaymantaa@unmsm.edu.pe

JESSICA MARGARITA LOYOLA ROMANÍ

Universidad Nacional MaYor de San Marcos

jloyolar@unmsm.edu.pe

\title{
ÉTICA Y DEONTOLOGÍA EN DEBATE. REGISTRO NACIONAL DE ABOGADOS SANCIONADOS POR MALA PRÁCTICA PROFESIONAL
}

\section{ETHICS AND DEONTOLOGY IN DEBATE. NATIONAL REGISTER OF LAWYERS SANCTIONED FOR PROFESSIONAL MALPRACTICE}

Cómo citar el artículo:

\begin{abstract}
Quiroz R, Limaynta C, Loyola J, (2021) Ética y Deontología en debate. Registro Nacional de Abogados sancionados por Mala Práctica Profesional. Derecho Global, Estudios sobre Derecho y Justicia, VI (19) https://DOI.org/10.32870/dgedj.v6i19.436 pp.167-207
\end{abstract}

Recibido: 15/01/2021 Aceptado: 11/07/21 


\title{
RESUMEN
}

El objetivo de la investigación es conocer la incidencia de las faltas a la ética y la deontología anotadas en el Registro Nacional de Abogados Sancionados por Mala Práctica Profesional (RNAS), a cargo del Ministerio de Justicia y Derechos Humanos (Decreto Legislativo N. ${ }^{\circ}$ 1265). El registro entró en vigencia el año 2017 y, desde esa fecha hasta diciembre de 2019, se registró un total de 789 abogados que habían recibido una serie de sanciones, como multas, suspensiones, separaciones y destituciones. Esta investigación es de tipo cuantitativa, descriptiva y de análisis documental. Se analizó una muestra de expedientes de abogados sancionados con la destitución, considerando que constituye una de las sanciones más graves que señala la norma. Se llegó a la conclusión de que la falta de integridad en la conducta de jueces y fiscales deriva en una serie de actos de corrupción, lo que genera un grave problema dentro del Sistema de Justicia en el Perú.

\section{Palabras clave}

Ética. Deontología. Corrupción. Integridad pública.

\begin{abstract}
The objective of the investigation is to know the impact of the lacks to ethics and deontology noted in the National Register of Lawyers Sanctioned for Professional Malpractice (RNAS), by the Ministry of Justice and Human Rights (Legislative Decree 1265). The Registry entered into force in 2017, from that date until December 2019 a total of 789 lawyers sanctioned with a series of mis faults, fine, suspension, separation and dismissal were registered. This research is quantitative, descriptive and documentary analysis. A sample of lawyers' files sanctioned with dismissal was analysed, considering that it constitutes one of the most serious sanctions indicated by the rule. It was concluded that the lack of integrity in the conduct of judges and prosecutors, which creates a serious problem within the justice system in Peru. Thus, of all institutions, the population regards the judiciary as the most corrupt, without any government being able to reverse such a situation, despite having approved a series of policies, plans and reforms from the State that have not had the greatest results.
\end{abstract}




\section{KEYWORDS}

Ethics. Deontology. Corruption. Public integrity.

Sumario: I. Introducción. 1. Conceptualización de Ética, Moral, Derecho y Deontología. 2. El Problema de la Integridad en el Sector Público. 3. La Corrupción. II. Metodología. III. Resultados. 1. Registro del Total de Abogados Sancionados Administrativamente (2017-2019). 2. Número de Abogados Destituidos en el Ejercicio del Cargo de Jueces o Fiscales. 3. Cargo y Nivel Jerárquico de Jueces y Fiscales Destituidos. 4. Género de Abogados Sancionados. 5. Lugar Geográfico (procedencia de los hechos sancionados). 6. Normas Legales Infringidas por Jueces y Fiscales. 7. Causas y Consecuencias de la Falta de Integridad en la Conducta de Jueces y Fiscales. IV. Conclusiones. 1. Recomendaciones. Bibliografía.

\section{INTRODUCCIÓN}

El objetivo general de la investigación es conocer la incidencia de las faltas a la ética y la deontología anotadas en el Registro Nacional de Abogados Sancionados por Mala Práctica Profesional (RNAS), a cargo del Ministerio de Justicia y Derechos Humanos (Decreto Legislativo N. ${ }^{\circ}$ 1265) en Perú. Y como uno de los primeros objetivos específicos, es desarrollar en la primera parte un escueto marco de referencia conceptual sobre los temas de ética, moral, deontología y corrupción, aspectos teóricos que orientarán la investigación y permitirán una mejor interpretación de los hallazgos. Se formula las siguientes interrogantes de investigación: ¿Cuál es el nivel de sanción impuesta a los abogados que ejercen la función pública de jueces o fiscales y el tipo de faltas sancionadas con mayor frecuencia por mala práctica profesional en aplicación del Decreto Legislativo $\mathrm{N}^{\circ}$ 1265? ¿Cuál es el número de abogados sancionados en función al cargo y nivel jerárquico de jueces y fiscales? ¿Cuál es el número de abogados sancionados en función al género y el lugar geográfico con mayor incidencia en la comisión de faltas sancionadas? ¿Qué normas legales han sido las más infringidas en la 
sanción impuesta a jueces y fiscales? ¿Cuáles son las causas y consecuencias de la falta de integridad en la conducta de los abogados que forman parte del sistema de justicia? La hipótesis de trabajo es que las sanciones impuestas por mala práctica profesional a los abogados que ejercen la función de jueces o fiscales dentro del Sistema de Justicia en el Perú y registradas en el RNAS, son en su mayoría por faltas leves (multas) que no reflejan el alto porcentaje de desaprobación y desconfianza hacia el Poder Judicial y el Ministerio Público, medición realizada por el Instituto Nacional de Estadística e Informática (INEI) (2020, p. 7), Transparencia Internacional (2019) y por Latinobarómetro (2018, p. 51), rechazo hacia conductas de transgresión a la ley, que en muchos casos debería llevarlos a la destitución. Es más, de todas las instituciones, la población considera al Poder Judicial como la más corrupta, sin que ningún gobierno haya podido revertir tal percepción, pese a haber aprobado una serie de políticas, planes y reformas desde el Estado sin mayores resultados. La investigación parte de la revisión de la literatura que permite darle sustento teórico al tema objeto de la investigación, como es la conducta ética y deontológica de los abogados, conductas que muchas veces pueden ser tipificadas como actos de corrupción. De tal forma que se utilice conceptos y términos claros en el análisis e interpretación de los hallazgos.

El estudio gira en torno a la aplicación de las siguientes normas:

- Registro Nacional de Abogados Sancionados con Mala Práctica Profesional (2016). Decreto Legislativo $N .^{\circ} 1265$. El gobierno emite este decreto bajo los siguientes considerandos:

Que, los Principios Básicos sobre la Función de los Abogados de las Naciones Unidas establecen que los abogados siempre obrarán de conformidad con la ley y normas éticas, manteniendo en todo momento el honor y dignidad de su profesión. Asimismo, los abogados están sujetos a sanciones disciplinarias, civiles y penales en relación con sus deberes y responsabilidades profesionales como agentes de la administración de justicia;

\section{DERECHO GLOBAL. ESTUDIOS SOBRE DERECHO Y JUSTICIA}


Que, las malas prácticas de los abogados afectan el derecho al debido proceso previsto en el inciso 3 del artículo 139 de la Constitución Política del Perú, asimismo socavan la confianza y generan incertidumbre en las instituciones de la administración de justicia, por lo que existe la necesidad pública de implementar un Registro Nacional de Abogados sancionados por mala práctica profesional, a fin de fortalecer la capacidad informativa de los justiciables.

- Reglamento del Registro Nacional de Abogados Sancionados con Mala Práctica Profesional (2017). Decreto Supremo N. ${ }^{\circ} 002-2017-J U S$. Reglamento que obliga a todas las entidades del Estado informar al MINJUS en el plazo de 48 horas, las sanciones impuestas a los abogados. Tal como su nombre lo indica, se inscribirán las sanciones recaídas en abogados que hayan incurrido en malas prácticas profesionales. Porotrolado, el acceso a esteregistro a cargo delMINJUS debe ser público y gratuito. Esta base de datos se encuentra en el portal web del Ministerio y funciona en estricta coordinación con los colegios profesionales de abogados del país, a fin de conocer la nómina de los abogados colegiados.

\section{Conceptualización de Ética, Moral, Derecho y Deontología}

El vocablo "ética" deriva de la raíz etimológica griega ethos, la cual está referida al carácter y la costumbre, elementos inherentes a la conducta del ser humano. Existe consenso entre los académicos en que la ética es una rama de la filosofía cuyo objeto de estudio es la moral. Es la perspectiva analítica para estudiar la naturaleza del fenómeno moral, que lleva a reflexionar sobre la mejor manera de vivir, las mejores costumbres que se deben practicar para hacer la vida más llevadera (Giusti \& Tubino, 2010).

El término "moral", del latín mos, moris, mores, también significa costumbre o modo de vida, por lo que es usado casi siempre como sinónimo de ética, al ser etimológicamente equivalentes. La moral como objeto de estudio de la ética prescribe cómo debe ser la conducta de los individuos, estableciendo normas, reglas y principios que guían la conducta humana, los cuales se manifiestan 
en la moralidad y la conciencia moral que conllevan a los individuos a asumir con responsabilidad las consecuencias de sus actos. Como tal, la moral es una práctica, autónoma y de carácter privado, que depende de la conciencia de cada individuo, pero que responde a un sistema de valores propios de una comunidad, en un lugar y época determinados.

La moral trata de la conducta humana respecto a elementos valorativos del bien y el mal, en tanto la ética estudia los fundamentos o bases con los cuales se reflexiona respecto a éstos, evalúa la conducta humana, así como lo referente a la moralidad. (Sanromán, González \& Villa, 2015, p. 318)

Por su lado, si distinguimos entre el derecho y la moral, se tiene que mientras el primero se traduce en normas jurídicas y es heterónoma, ya que la conducta externa manifiesta del individuo permite la convivencia humana y es vigilada y sancionada mediante los mecanismos coercitivos del Estado; la segunda, al ser autónoma, es sancionada por la conciencia del individuo. "La diferencia esencial entre el derecho y la moral estriba en que el derecho tiene por objeto las relaciones entre personas, mientras que la moral recae sobre el hombre en cuanto individuo" (Sanromán, González \& Villa, 2015, p. 317). De esa manera, la ética jurídica se entiende como parte de la ética general que estudia la conducta humana en el marco de un ordenamiento jurídico (Martínez, 2002).

Por último, "deontología" parte de los términos griegos deón, deontos, que significan "lo que es necesario", "preciso o debido", "deber", "obligación” y del sufijo "logos" referido al "tratado, estudio". Se define como una parte de la ética que estudia los deberes morales (Pérez, 2007). Los autores Sanromán, González y Villa (2015) señalan:

En lo que respecta a la deontología, su objeto de estudio son los principios del deber y las normas morales; asociada con la Axiología forma parte de la ética normativa; hay dos principales tipos de deontología; una el deber ser de nuestra vida cotidiana; es decir si debemos hacer o no lo correcto en alguna situación, y la segunda que determina el comportamiento respecto a las reglas planteadas como necesarias para la convivencia o desarrollo, por lo 
tanto, la deontología tiene la intención de actuar conforme a la ética y a lo establecido. (La primera es la deontología aplicada y la segunda es prescriptiva).

\section{El Problema de la Integridad en el Sector Público}

La integridad en el ámbito público está referida al comportamiento de los funcionarios y servidores en el marco de principios y valores morales, que en la actualidad se encuentra en una profunda crisis generalizada. Estas consideraciones morales no son observadas por aquellos que realizan determinadas funciones públicas y que tienen la enorme responsabilidad de administrar los escasos recursos del Estado, con los que se debe proveer a la ciudadanía de servicios esenciales como educación, salud, infraestructura y seguridad, los cuales son derechos fundamentales que permiten asegurar mínimos niveles de calidad de vida. La Organización para la Cooperación y el Desarrollo Económicos (2017) la define como la adhesión a los valores, principios y normas éticos que permiten priorizar el interés público sobre los privados. Para las Naciones Unidas (2017), "El concepto de integridad, abarca entre otras cosas, probidad, imparcialidad, equidad, honestidad y veracidad en todos los asuntos que afectan su trabajo y su estatus" (p. 12).

Asimismo, para garantizar una eficiente administración pública se requiere de políticas públicas y planes estratégicos que operacionalicen estas políticas. Para ello, no solo es menester que el funcionario público tenga la formalidad del respaldo legal, sino que su conducta debe estar avalada por la integridad en la ejecución de dichos planes y programas, con transparencia y mecanismos adecuados de control interno y rendición de cuentas, así como un efectivo reglamento de sanciones en casos de corrupción. Así, se pretende evitar la corrupción sistémica, ese círculo vicioso que se repite por décadas y en todos los gobiernos de turno, tanto en el ámbito penal como en el administrativo, y que muchas veces se da con la "captura de las políticas públicas", la cual se evidencia inclusive en el diseño y la aprobación de leyes y políticas públicas en los que prima el interés privado (Organización para la Cooperación y el Desarrollo Económicos, 2017). 


\section{La Corrupción}

La palabra "corrupción" deriva del latín corrumpere, que significa "sobornar", "falsificar", "dañar", "echar a perder” (Spittler, 2012). Se define como los actos secretos y privados que llevan a transgredir las normas a fin de lograr una ventaja ilegítima (Palomino, 2018). En tanto, Piana y Arévalo (2019) citan la Resolución N. ${ }^{\circ} 1 / 18$ de la Comisión Interamericana de Derechos Humanos $(\mathrm{CIDH})$, que "define la corrupción como un complejo fenómeno que afecta a los derechos humanos en su integralidad, así como el derecho al desarrollo; debilita la gobernabilidad y las instituciones democráticas, socaba el Estado de derecho y exacerba la desigualdad" (p. 4). Por su parte, Klitgaard (1998) la resume en la siguiente fórmula: $\mathrm{C}=\mathrm{M}+\mathrm{D}-\mathrm{R}$, es decir, corrupción es igual a monopolio más discrecionalidad menos rendición de cuentas. La Comisión de Alto Nivel Anticorrupción (2017) también la define: "El mal uso del poder público o privado para obtener un beneficio indebido; económico, no económico o ventaja; directa o indirecta; por agentes públicos, privados o ciudadanos; vulnerando principios y deberes éticos, normas y derechos fundamentales" (p. 16).

Se pueden distinguir dos tipos de corrupción como las más recurrentes en los funcionarios del Estado: uno en el ámbito penal, que implica el peculado, la colusión, la malversación, el tráfico de influencias, el enriquecimiento ilícito, el cohecho, la concusión y la negociación incompatible; y otro en el ámbito administrativo, que alude al conflicto de intereses, la ventaja indebida, el nepotismo, el abuso de posición personal y el incumplimiento del deber de cautelar los bienes del Estado (Comisión de Alto Nivel Anticorrupción, 2017, p.20).

A nivel mundial la lucha contra la corrupción ha sido objeto de la aprobación de numerosos instrumentos jurídicos, tanto de carácter nacional como internacional. Entre estos últimos tenemos la Convención Interamericana Contra la Corrupción (1996) de la Organización de Estados Americanos, cuyo primer propósito fue:

\section{DERECHO GLOBAL. ESTUDIOS SOBRE DERECHO Y JUSTICIA}


"1. promover y fortalecer el desarrollo, por cada uno de los Estados Partes, de los mecanismos necesarios para prevenir, detectar, sancionar y erradicar la corrupción". La Convención de las Naciones Unidas contra la Corrupción (CNVCC, 2003), que contempla cinco niveles de lucha contra la corrupción: la previsión, la represión penal, la recuperación de activos, la cooperación internacional y la asistencia técnica. Finalmente, la Carta Iberoamericana de Ética e Integridad en la Función Pública (2018), tiene el objetivo de "promover la integridad de los responsables y servidores públicos en todos sus niveles, entendiéndose por tal una actuación continuamente coherente con los valores y principios relevantes de la ética del servicio público".

Por otro lado, el Perú ha reiterado su compromiso de luchar contra la corrupción en otros espacios internacionales como son la Organización para la Cooperación y Desarrollo Económicos (OCDE), Foro Económico de Asia Pacífico (APEC), Comunidad de Estados Latinoamericanos y Caribeños (CELEC), Cumbres de las Américas, entre otros, siendo que además se ha comprometido a la ejecución de los Objetivos de Desarrollo Sostenible de la Organización de las Naciones Unidas, que tiene dentro de sus metas el reducir la corrupción y el soborno en todas sus formas y crear instituciones eficaces, responsables y transparentes a todos los niveles. (Decreto Supremo N. ${ }^{\circ}$ 092-2017-PCM)

En el ámbito nacional, en las dos últimas décadas se ha aprobado un amplio marco normativo para la lucha contra la corrupción. Así tenemos la Constitución Política del Perú del año 1993 , los artículos $39 .{ }^{\circ}, 41 .^{\circ}$ y $44{ }^{\circ}$ referidos a la función pública.

El año 2002, se creó el Acuerdo Nacional (AN), el cual integró a autoridades del más alto nivel del sector público y a representantes de organizaciones políticas y de la sociedad civil, a fin de sentar las bases de una "política de Estado", como un espacio de diálogo y concertación. Tiempo después, en 2013, la Ley N. ${ }^{\circ} 29976$ creó la Comisión de Alto Nivel Anticorrupción (CAN), cuyo Artículo 1 señala: "Créase la Comisión de Alto Nivel Anticorrupción, con el objeto de articular esfuerzos, coordinar acciones y proponer políticas, de corto, mediano y largo plazo dirigidas a prevenir y combatir la corrupción en el país". 
Tras ello, en 2017, se promulgó el Decreto Supremo N. ${ }^{\circ}$ 092-2017-PCM que aprobó la Política Nacional de Integridad y Lucha contra la Corrupción por iniciativa de la CAN, en la que se establece, como órganos de control superior, encargados de la investigación, denuncia, juzgamiento y sanción, al Poder Judicial, el Ministerio Público y la Contraloría General de la República. Por último, el año 2018, el Poder Ejecutivo promulgó el Decreto Supremo N. ${ }^{\circ}$ 0442018-PCM sobre el Plan Nacional de Integridad y Lucha contra la Corrupción 2018-2021, con dos enfoques: prevención y combate contra la corrupción. No obstante, en el Perú se tienen registros de los actos de corrupción desde la época colonial y durante la vida republicana. Corrupción entendida como el mal uso del poder político-burocrático, por parte de camarillas de funcionarios, coludidos con mezquinos intereses privados, para así obtener ventajas económicas o políticas contrarias a las metas del desarrollo social mediante la malversación o el desvío de recursos públicos, y la distorsión de políticas e instituciones (Quiroz, 2013).

\section{Metodología}

La presente investigación, de tipo cuantitativa, descriptiva y de análisis documental, se centra en el análisis de los expedientes que se encuentran en el Registro Nacional de Abogados Sancionados por Mala Práctica Profesional (RNAS), los cuales fueron consultados en la página web del Ministerio de Justicia y Derechos Humanos. En una primera etapa, se identificó y seleccionó el expediente de los abogados sancionados con multa, separación o destitución en los años 2017-2019, en el ejercicio independiente de la profesión o en el ejercicio de la función jurisdiccional, en calidad de jueces en el Poder Judicial o fiscales en el Ministerio Público. En una segunda fase, se trabajó solo con el registro de los abogados sancionados con destitución, considerando que esta constituye una de las sanciones más graves impuestas desde 2017, año de creación del Registro, hasta 2018, fecha en que se desactivó el Consejo Nacional de la Magistratura (por denuncias de corrupción), organismo constitucionalmente autónomo encargado de nombrar, ratificar y sancionar a jueces y fiscales de todas las instancias del Poder

\section{DERECHO GLOBAL. ESTUDIOS SOBRE DERECHO Y JUSTICIA}


Judicial y el Ministerio Público. Para el análisis de los expedientes, se elaboró una tabla de doble entrada con los siguientes datos de los abogados sancionados: apellidos y nombres, función jurisdiccional, género, lugar desde donde se solicitó la sanción, norma legal objeto de infracción y conducta sancionada. Asimismo, se trabajó con la siguiente matriz de variables e indicadores, la cual guio el curso de la investigación.

Tabla 1. Matriz de variables e indicadores

\section{Variable}

Elaboración propia.

\section{Indicadores}

a. Número de abogados sancionados

b. Número de abogados destituidos (jueces y fiscales)

Abogados sancionados en aplicación del Decreto Legislativo N. ${ }^{\circ} 1265$ y su reglamento

d. Género de abogados sancionados

e. Lugar geográfico (ocurrencia de faltas sancionadas)

f. Normas legales infringidas por jueces y fiscales

Cabe distinguir los tipos de sanciones que el reglamento del Decreto Legislativo N. ${ }^{\circ} 1265$ impone:

- Multa. El pago de una suma de dinero por infringir una norma.

- Destitución de un puesto o cargo. Expulsión de una persona del cargo que ocupa por parte de la autoridad competente.

- Separación temporal del colegio al que pertenece el abogado. Apartar del colegio profesional al que pertenece por alguna falta cometida.

- Suspensión temporal en el ejercicio de la profesión y/o cargo. Cese en el ejercicio de una profesión. 
Las tablas y gráficos se elaboraron empleando el análisis descriptivo y de frecuencias de los contenidos de las resoluciones que se encuentran en formato PDF en el portal del RNAS-MINJUS. Se sistematizaron las frecuencias y se identificó el expediente de los abogados sancionados con la destitución, que se expresó en términos porcentuales frente a los totales revisados. Por otro lado, en cuanto al diseño muestral, la población objetivo estuvo constituida por todos los expedientes de abogados destituidos por el antiguo CNM durante los años 2017-2018, registrados en el RNAS del MINJUS, los cuales suman un total de 126. Se utilizó el diseño del muestreo aleatorio simple, dado que los expedientes tienen similares características en los años de estudio. El tamaño de muestra se determinó de acuerdo con la ecuación de Pérez (2005):

$$
n=\frac{Z_{\left(1-\frac{\alpha}{2}\right)}^{2} N p q}{e^{2}(N-1)+Z_{\left(1-\frac{\alpha}{2}\right)}^{2} p q}
$$

$Z_{\left(1-\frac{\alpha}{2}\right)}^{2}$ V Valor crítico de la distribución normal estándar con $94 \%$ de confianza
$\quad=1.88$
$\sqrt{N}:$ Tamaño de la población $=126$
$\bar{p}:$ Proporción de sanciones de destitución $=0.5$
$\bar{e}:$ Error de muestreo $=0.07$
Remplazando $\mathrm{n}=74.76=75$ expedientes

La selección de la muestra de 75 expedientes se realizó mediante el uso del programa estadístico SPSS V25, lo que permitió arribar a los resultados que se exponen en la siguiente tabla. 
Tabla 2. Tamaño de la población y muestra

\begin{tabular}{|c|c|c|}
\hline Año & Tamaño de la población & Tamaño de la muestra \\
\hline 2017 & 87 & 53 \\
\hline 2018 & 39 & 22 \\
\hline Total & 126 & 75 \\
\hline
\end{tabular}

Elaboración propia.

\section{RESULTADOS}

Los resultados que se muestran a continuación están referidos a la sanción impuesta a la conducta de los abogados, que en calidad de jueces o fiscales forman parte del Sistema de Justicia en el Perú, sistema conformado por un conjunto de organismos encargados directa o indirectamente de administrar justicia: Poder Judicial, Ministerio Público, Tribunal Constitucional, Jurado Nacional de Elecciones, entre otros. De ellos, el Poder Judicial es la institución clave en la sociedad; sus funciones jurisdiccionales están direccionadas a garantizar el derecho fundamental de acceso a la justicia, tal como lo señala el Tribunal Constitucional:

El ejercicio de la potestad jurisdiccional o la potestad de administrar justicia comprende, en lo esencial, lo siguiente: la tutela de los derechos fundamentales, los derechos ordinarios e intereses legítimos; la sanción de los actos delictivos; el control difuso de la constitucionalidad; y el control de la legalidad de los actos administrativos. (Sentencia N. ${ }^{\circ}$ 0023-2003-AI/TC, p. 11)

Este poder del Estado, autónomo e independiente, garantiza el Estado de derecho (Sabsay, 2004); sin embargo, la falta de integridad en la conducta de una cantidad importante de jueces y fiscales, además de la politización, impide el funcionamiento imparcial de la justicia, contribuyendo de esa manera a la 
corrupción (Naciones Unidas, 2014). Sendos diagnósticos, así como casos objetivos de conocimiento público, dan cuenta de redes de corrupción de gran entramado que se han apoderado de casi todo el Poder Judicial y el Ministerio Público. Estos problemas explican el cuestionamiento a la conducta procesal de jueces y fiscales, cuyas resoluciones muchas veces están intencionalmente direccionadas al amparo de la discrecionalidad en el ejercicio de sus funciones.

Quiñones (2016) da cuenta de que en estos nexos de corrupción participan, no solo jueces y fiscales, sino diversos operadores de justicia, tales como relatores, secretarios judiciales, asistentes de juzgados y trabajadores de mesa de partes. Las acciones inmorales de estos trabajadores abarcan la elaboración parcializada de resoluciones judiciales, la recepción de escritos fuera de plazo, la desaparición de expedientes de los juzgados, el cambio de fecha de audiencias y las resoluciones de sentencias elaboradas fuera de los juzgados. Muchas veces suelen ser los mismos interesados, en componenda con el secretario o el juez, quienes asumen o sustituyen tan delicada responsabilidad, siendo el dinero el medio que lo permite.

\section{Registro del Total de Abogados Sancionados Administrativamente (2017-2019)}

El nivel de sanción impuesta a los abogados que ejercen la función pública, según el Registro Nacional de Abogados Sancionados por Mala Práctica Profesional a diciembre de 2019, es de un total de 789 abogados con diferentes tipos de sanciones establecidas en la norma (multa, destitución, separación, suspensión). Para la investigación solo se consideró la sanción de destitución impuestas a los jueces o fiscales en el ejercicio del cargo durante los años 2017 y 2018, desde la vigencia del Registro hasta la fecha en que se desactivó el Consejo Nacional de la Magistratura cuya función era, entre otros, la de sancionar a los magistrados del Poder Judicial y del Ministerio Público.

\section{DERECHO GLOBAL. ESTUDIOS SOBRE DERECHO Y JUSTICIA}


Tabla 3. Número de abogados sancionados (2017-2019)

\begin{tabular}{|ccccc|}
\hline Año & Multa & Destitución & Separación & Suspensión \\
\hline 2017 & 45 & 85 & 5 & 2 \\
2018 & 176 & 39 & 2 & 2 \\
2019 & 420 & 2 & - & 11 \\
Total & 641 & 126 & 7 & 15 \\
$\%$ & 81.24 & 15.97 & 0.89 & 1.90 \\
\hline Total & & & 789 & \\
\hline
\end{tabular}

Fuente: Registro Nacional de Abogados Sancionados por Mala Práctica Profesional del MINJUS. Elaboración propia.

Los datos desagregados de la tabla anterior indican que, de acuerdo a su tipo, la mayor cantidad de sanciones impuestas contempladas en la Ley N. 1265 y su Reglamento fue la multa, que representa el $81,24 \%$ del total de sancionados y es la que se impone ante faltas leves. Le sigue con menor incidencia $(15,97 \%)$ la destitución, en tanto que la separación y la suspensión alcanzan un mínimo porcentaje $(2,79 \%)$. De acuerdo a estos datos, el número de sanciones impuestas no refleja el alto porcentaje de desaprobación y desconfianza de la población hacia el Sistema de Justicia (Transparencia Internacional, 2019; Latino barómetro, 2018 y el INEI, 2020). Lo que significa que muchos casos de inconducta funcional de jueces o fiscales no son denunciados con la consecuente impunidad, y si se denuncia, los hechos suelen ser minimizados y sancionados de forma benigna, tal como nos muestra la Tabla 3.

Lo cual nos lleva a analizar la práctica profesional del abogado, no obstante que cumple una función esencialmente social en defensa de la tutela de bienes jurídicos, tanto en el ejercicio privado al defender casos particulares generados por conflictos de intereses, como frente al órgano jurisdiccional o administrativo dentro del Estado, su ejercicio profesional ha venido siendo cuestionado al no estar alineado a los principios, valores, normas morales y deontológicas, que se 
traducen en los códigos de ética de sus respectivos colegios profesionales y en el Código de Ética de la Función Pública (Ley N. ${ }^{\circ}$ 27815), con la consiguiente desconfianza de la población. Ello ha dado lugar al desprestigio del abogado, que lejos de ser visto como un defensor de la justicia y de la legalidad, direccionado al bien común y a la convivencia pacífica, es percibido como uno de los profesionales más deshonestos, como señala Ramírez (2012) : “Todas las sociedades consideran al abogado como una persona sin ética” (p. 36), que actúa con viveza, casi siempre al margen de valores morales, y con escasa preparación en Derecho. Se considera que la justicia significa poco para él, ya que en muchos casos es quien contribuye a crear o agudizar los conflictos.

Además, si ejerce su profesión de manera liberal o como parte de un estudio jurídico, se somete y entra a la dinámica de la corrupción: debe pagar para tramitar los documentos a una serie de intermediarios: "procuradores", "tramitadores" y "tipeadores" que cuentan con gran experiencia y mantienen una red de conocidos y negociadores alrededor de los juzgados. Esto constituye una práctica diaria e inevitable (Mujica, 2011, p. 91).

\section{Número de Abogados Destituidos en el Ejercicio del Cargo de Jueces o Fiscales}

Tabla 4. Número de jueces y fiscales destituidos (2017-2018)

\begin{tabular}{|lcccc|}
\multicolumn{1}{c}{ Abogados } & $\mathbf{2 0 1 7}$ & $\mathbf{2 0 1 8}$ & Total & \% \\
\hline Jueces & 39 & 14 & 53 & 71 \\
Fiscales & 14 & 8 & 22 & 29 \\
Total & 53 & 22 & 75 & 100
\end{tabular}

Fuente: Registro Nacional de Abogados Sancionados por Mala Práctica Profesional del MINJUS. Elaboración propia.

El número de abogados sancionados en función al cargo y nivel jerárquico de jueces y fiscales, de acuerdo a los datos de la tabla anterior se tiene que mientras 
el 71\% de abogados destituidos fueron los jueces en sus diferentes cargos y niveles, solo el $29 \%$ correspondió a los fiscales.

El mayor número de jueces sancionados, muestra cómo la población, sobre todo la de menores recursos, sufre a diario las consecuencias de una serie de prácticas y componendas perfectamente articuladas entre quienes forman parte de la administración de justicia, que actúa con lentitud, ineficiencia y más de las veces, con prácticas corruptas, permitiendo la impunidad y "retardando el desarrollo económico y social del país, y afectando la credibilidad de las instituciones del Sistema de Justicia" (Comisión Especial para la Reforma Integral de la Administración de Justicia, 2004, p. 149).

Frente a esta realidad, diferentes gobiernos en los últimos cincuenta años han emprendido, en un sinnúmero de oportunidades, la ansiada reforma del Poder Judicial. Paradójicamente, ahora se sabe que los casos más graves de corrupción en perjuicio del Estado y de la población se dieron precisamente en los gobernantes que más pregonaban luchar contra ella. Una de estas reformas y la más importante, según diversos juristas, se emprendió el 2004, durante el periodo presidencial de Alejandro Toledo, con la conformación de la Comisión Especial para la Reforma Integral de la Administración de Justicia (CERIAJUS), que formuló el Plan Nacional de Reforma Integral de la Administración de Justicia, con la participación de miembros del sistema de justicia, los colegios de abogados, las facultades de Derecho y los representantes de la sociedad civil.

Sobre esa comisión, Pásara (2016) anota:

Desde una reforma constitucional hasta medidas concretas para mejorar el acceso a la justicia, pasando por la modernización del despacho judicial, la Comisión abarcó diversos terrenos y formuló proposiciones específicas. Algunas se tradujeron en leyes; las más importantes se encarpetaron. En definitiva, la justicia tampoco fue tocada por este tercer intento de reforma. No obstante que entre 2004 y 2008 se dobló el presupuesto destinado al Poder Judicial, el péndulo oficial volvió hacia el lado de la desatención real y el desentendimiento profundo del problema. 
Lamentablemente, dicha reforma solo quedó en propuestas por falta de voluntad política del gobierno de turno. Ello se debió quizá a que nunca se tuvo una real intención de aplicarla o, como refieren Piana \& Arévalo (2019): "la corrupción no es un problema del Poder Judicial sino un problema social ya que es un desvalor que afecta a la ciudadanía en su conjunto" p. 9).

Los problemas que ha enfrentado el proceso de reforma de justicia en la región explican la profunda crisis de legitimidad que experimenta el sistema, marcada por baja confianza y por la percepción generalizada de que el sistema es corrupto, ineficaz y favorece la impunidad. (Naciones Unidas, 2013, p. 120)

Como se puede ver, la situación es bastante compleja en el país, a tal punto que los seis presidentes elegidos democráticamente en las tres últimas décadas, a excepción de Valentín Paniagua, que dirigió el gobierno de transición (20002001), así como los líderes políticos más importantes, quienes en la actualidad se encuentran en condición de sentenciados, investigados o prófugos de la justicia; incluso un ex presidente suicidado. Todos estos gobernantes han sido acusadas de corrupción, lo que muestra que esta es un complejo fenómeno sistemático, tal como señalaba con crudeza el exsecretario general de las Naciones Unidas.

La corrupción es una plaga insidiosa que tiene un amplio espectro de consecuencias corrosivas para la sociedad. Socava la democracia y el estado de derecho, da pie a violaciones de los derechos humanos, distorsiona los mercados, menoscaba la calidad de vida y permite el florecimiento de la delincuencia organizada, el terrorismo y otras amenazas a la seguridad humana. ... La corrupción afecta infinitamente más a los pobres porque desvía los fondos destinados al desarrollo, socava la capacidad de los gobiernos de ofrecer servicios básicos, alimenta la desigualdad y la injusticia y desalienta la inversión y las ayudas extranjeras. (Annan, 2004, p. iii) 


\section{Cargo y Nivel Jerárquico de Jueces y Fiscales Destituidos}

Tabla 6. Jerarquía de jueces destituidos (2017-2018)

\begin{tabular}{lccc}
\multicolumn{1}{c}{ Jueces } & $\mathbf{2 0 1 7}$ & $\mathbf{2 0 1 8}$ & Total \\
Presidente de Corte Superior & 1 & 1 & 2 \\
Juez superior & 4 & 1 & 5 \\
Juez penal especializado & 12 & 1 & 13 \\
Juez civil especializado & 6 & 1 & 7 \\
Juez mixto & 6 & 8 & 14 \\
Juez de paz letrado & 9 & 1 & 10 \\
Juez constitucional & 1 & 1 & 2 \\
Total & 39 & 14 & 53
\end{tabular}

Fuente: Registro Nacional de Abogados Sancionados por Mala Práctica Profesional del MINJUS.

Elaboración propia.

Tabla 7. Jerarquía de fiscales destituidos (2017-2018)

\begin{tabular}{lccc}
\multicolumn{1}{r}{ Fiscales } & $\mathbf{2 0 1 7}$ & $\mathbf{2 0 1 8}$ & Total \\
Fiscal supremo & 1 & - & 1 \\
Fiscal superior & 1 & - & 1 \\
Fiscal provincial & 12 & 8 & 20 \\
Total & 14 & 8 & 22
\end{tabular}

Fuente: Registro Nacional de Abogados Sancionados por Mala Práctica Profesional del MINJUS.

Elaboración propia.

Si se comparan los datos proporcionados acerca de la destitución de jueces y fiscales, se evidencia que en los años 2017 y 2018, existe mayor número de jueces destituidos de su cargo (53). Esto se explica porque, de acuerdo con la naturaleza de la función jurisdiccional que ejercen, son los jueces quienes deciden en el proceso judicial, sea en forma individual o colegiada, sobre una determinada controversia o incertidumbre jurídica, por lo general bajo el principio de discrecionalidad en 
la interpretación de la norma; son ellos también quienes en algunos casos toman decisiones arbitrarias y carentes de toda argumentación legal. A la vez, la mayoría de los jueces destituidos corresponden al ámbito especializado en lo penal (13), hecho que resulta muy grave si consideramos que, por la función jurisdiccional que ejercen, deben resolver casos ligados al delito, lo que impacta directamente en la libertad de los individuos, uno del derecho fundamental más importantes de la persona, tal como lo señala el Tribunal Constitucional (2004):

El ejercicio de la potestad jurisdiccional o la potestad de administrar justicia comprende, en lo esencial, lo siguiente: la tutela de los derechos fundamentales, los derechos ordinarios e intereses legítimos; la sanción de los actos delictivos; el control difuso de la constitucionalidad;

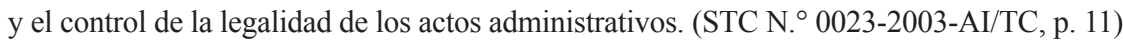

Todo ello no hace más que agravar la profunda crisis de la justicia en el país. Por este motivo, el 2018 el gobierno presentó un proyecto de ley a fin de promover la probidad de los abogados, en cuya exposición de motivos señalaba:

[...] el presente proyecto tiene la finalidad de aprobar medidas orientadas a promover la probidad en el ejercicio profesional de los abogados, teniendo presente la función social que desempeñan, la misma que cumple un rol preponderante que debe contribuir de manera decidida en la lucha contra la corrupción, particularmente en el ámbito del Sistema Judicial. (Proyecto de Ley N. $\left.{ }^{\circ} 3164 / 2018-P E\right)$

De igual modo, es menester recordar que la actuación de los colegios profesionales, cuya misión es velar por el ejercicio de la profesión en el marco del cumplimiento de las normas contenidas en los códigos de ética, es de notoria ineficiencia, puesto que prima un espíritu de cuerpo antes que el derecho de la sociedad y de los más desposeídos de contar con una defensa justa y proba. Al respecto, el proyecto de ley proponía:

[...] los Colegios de Abogados deben adoptar medidas efectivas de carácter preventivo y sancionador para promover la ética y responsabilidad profesional

\section{DERECHO GLOBAL. ESTUDIOS SOBRE DERECHO Y JUSTICIA}


en sus agremiados, de lo contrario, se vacía de contenido la obligatoriedad de la colegiatura profesional, perdiendo ésta toda razón de ser. (Proyecto de Ley N. $\left.{ }^{\circ} 3164 / 2018-\mathrm{PE}\right)$

No obstante que las denuncias son numerosas sobre el comportamiento ético de sus miembros, son escasos los abogados sancionados por los tribunales de ética, lo cual puede ser explicado por la profunda crisis de valores que vive el país y que debe inspirar la transformación del sistema judicial, comprometiendo a las nuevas generaciones de abogados (Albán, 2018).

\section{Género de Abogados Sancionados}

Tabla 5. Abogados sancionados por género

\begin{tabular}{lcccc}
\multicolumn{1}{c}{ Abogados } & $\mathbf{2 0 1 7}$ & $\mathbf{2 0 1 8}$ & Total & \% \\
\hline Varones & 50 & 19 & 69 & 92 \\
Mujeres & 3 & 3 & 6 & 8 \\
Total & 53 & 22 & 75 & 100
\end{tabular}

Fuente: Registro Nacional de Abogados Sancionados por Mala Práctica Profesional del MINJUS. Elaboración propia.

El número de jueces o fiscales sancionados en función al género, de acuerdo a la información recopilada de la muestra, nos permite conocer que en su gran mayoría (92\%) fueron los jueces o fiscales varones los destituidos. Por su parte, las abogadas mujeres sancionadas solo representan el $8 \%$. Esto se explica, en parte, por el menor número de mujeres que ejercen la función jurisdiccional, es así que el sistema de justica descansa en mayor porcentaje en el personal masculino. En tanto que las mujeres en su mayoría se desempeñan como juezas de familia. A la vez, hay pocas mujeres que laboran en las instancias superiores, entre otras razones por las limitaciones de la maternidad y la familia, que impiden asumir mayores 
responsabilidades (Huaita, 2019). Por ejemplo, se tiene que de los 261 jueces y juezas que se incorporaron al poder judicial el año 2016, solo el 33\% fueron mujeres y $77 \%$ varones. En el caso de los jueces y juezas superiores fueron nombrados: solo 7 mujeres (15\%) frente a 39 varones (85\%) (MIMP, 2017, p. 267).

Si bien es cierto que actualmente es una mujer la fiscal suprema, existen marcadas diferencias entre las fiscalías provinciales, donde el 61,6\% de fiscales en ejercicio del cargo son varones (1 092), mientras que en las fiscalías adjuntas de provincias, las mujeres representan el 51,66\% (MIMP,2017, p. 268).

De acuerdo a Huaita, Chanjan y Saravia, 2019, algunos estudios parecerían identificar que cuando se cuenta con un importante contingente de mujeres, habría menores niveles de corrupción en las instituciones, éste debate sobre la supuesta "superioridad moral de las mujeres" ha llevado a propuestas de política pública en varios países de la región, entre ellos el Perú. En el contexto nacional, un análisis de genero respecto a la Encuesta Anticorrupción 2017 arroja que las mujeres reciben menos propuestas de corrupción en los espacios que tienen menos contactos; por el contrario, dichas propuestas aumentan para los hombres, ya que están más expuestos a incurrir en actos de corrupción (Huaita, diciembre de 2018). 


\section{Lugar Geográfico (procedencia de los hechos sancionados)}

Tabla 8. Lugar de procedencia

$\begin{array}{lccc} & \mathbf{2 0 1 7} & \mathbf{2 0 1 8} & \text { Total } \\ \text { Áncash } & 7 & 5 & 12 \\ \text { Arequipa } & 4 & - & 4 \\ \text { Amazonas } & 1 & 1 & 2 \\ \text { Apurímac } & 1 & - & 1 \\ \text { Ayacucho } & - & 1 & 1 \\ \text { Cajamarca } & 1 & - & 1 \\ \text { Loreto } & 2 & - & 2 \\ \text { Lima } & 9 & 2 & 11 \\ \text { Callao } & - & 1 & 1 \\ \text { Cerro de Pasco } & 2 & - & 2 \\ \text { Ica } & 1 & 1 & 2 \\ \text { Huánuco } & 3 & - & 3 \\ \text { Junín } & 1 & - & 1 \\ \text { Lambayeque } & 3 & - & 3 \\ \text { La Libertad } & - & 3 & 3 \\ \text { Madre de Dios } & 2 & 1 & 3 \\ \text { San Martín } & 3 & 1 & 4 \\ \text { Piura } & - & 2 & 2 \\ \text { Puno } & 4 & 1 & 5 \\ \text { Ucayali } & 5 & 2 & 7 \\ \text { Tacna } & 1 & - & 1 \\ \text { Tumbes } & 1 & 1 & 2 \\ \text { Total } & 53 & 22 & 75\end{array}$

Elaboración propia.

De acuerdo con los expedientes analizados, los casos de jueces y fiscales sancionados con la destitución se concentraron en el distrito judicial de la región Áncash (12), seguido de la región Lima y Lima Metropolitana (11) y la región Ucayali (7). Finalmente, si bien se reportan cinco casos en Puno, en el resto de las regiones los casos no pasan de los cuatro sancionados. Cabe precisar que el lugar geográfico no determina la cantidad de eventos relacionados a la corrupción. Sin embargo, la Región Áncash tuvo el mayor número de magistrados destituidos (12), esto se debe al 
alto movimiento económico generado como consecuencia del canon minero otorgado a los gobiernos locales y regionales, lo que derivó en múltiples denuncias de actos de corrupción. En cuanto a la Región Lima y Lima Metropolitana, la alta incidencia (11) se explica por su condición de capital de la República, por su densidad poblacional (11 millones de habitantes) y por ser la sede de la mayoría de órganos jurisdiccionales en comparación con otras regiones del país.

\section{Normas Legales Infringidas por Jueces y Fiscales}

Es importante conocer la fundamentación jurídica que sustenta las sanciones impuestas a los abogados en función a la naturaleza de la infracción cometida.

A continuación, se muestra los instrumentos normativos más transgredidos y que han dado lugar a las sanciones impuestas a jueces y fiscales.

Tabla 9. Instrumentos normativos aplicados en la destitución de jueces y fiscales (2017-2018)

\section{Instrumentos normativos}

1 Constitución Política del Perú de 1993

- $\quad$ Artículo 139 , inciso 5.

14

$2 \quad$ Ley de la Carrera Judicial

- $\quad$ Artículo 34, inciso $1 .^{\circ}$

- $\quad$ Artículo 48, inciso $13 .^{\circ}$

- Artículo 48, inciso $12 .^{\circ}$

3 Ley Orgánica del Ministerio Público

- $\quad$ Artículo $1 .^{\circ}$

\section{Total}


4 Reglamento de Organización y Funciones de la Fiscalía

Suprema de Control Interno del Ministerio Público

- $\quad$ Artículo 23, inciso g)

- $\quad$ Artículo 23, inciso a)

- $\quad$ Artículo 23, inciso d)

5 Código de Ética del Ministerio Público

- Artículo 3. ${ }^{\circ}$

- $\quad$ Artículo $1 .^{\circ}$

- $\quad$ Artículo 8. ${ }^{\circ}$

El análisis de las resoluciones registradas en el RNAS muestra que los instrumentos normativos que sustentan la sanción administrativa de destitución a jueces y fiscales, y que a su vez han sido las más transgredidas son diversas: van desde la Constitución hasta las leyes orgánicas y el código de ética del Ministerio Público. De ellos, la Ley de la Carrera Judicial y, luego, la Constitución Política son los instrumentos normativos más transgredidos y, por ende, más citados en la fundamentación jurídica que sustenta la sanción. Sin embargo, es de advertir que solo siete fiscales fueron sancionados por vulnerar el Código de Ética del Ministerio Público y en ningún caso se hace mención del Código de Ética del Poder Judicial; así, solo se refieren a la Ley Orgánica del Poder Judicial y a la Ley de la Carrera Judicial en las resoluciones materia de estudio. Por otro lado, aunque se encuentra vigente la Ley del Código de Ética de la Función Pública (Ley N. ${ }^{\circ}$ 27815 y su Reglamento), sin embargo, estas normas no han sido consideradas como fundamento de derecho en las sanciones que involucran el ejercicio de la función pública de jueces y fiscales. 
Tradicionalmente se entiende que el ejercicio del Derecho se encuentra circunscrito al plano estrictamente normativo; esto es, al entramado de relaciones jurídicas que se generan en virtud de la promulgación de las normas jurídicas. El ejercicio del derecho se enfocaría en la interpretación y aplicación de las normas jurídicas, las cuales establecen los parámetros de actuación en base a las cuales se deben resolver las controversias. (Quiñones, 2018, p. 36)

A continuación, se describe los instrumentos normativos más citados en las sanciones impuestas:

- Constitución Política del Perú. Es la norma de mayor jerarquía; contiene principios, normas y reglas que constituyen los derechos fundamentales de las personas, así como la organización del Estado y sus funciones. En los casos analizados, la mayoría de las destituciones de jueces y fiscales se enmarcaron en la transgresión de los principios y derechos de la función jurisdiccional (artículo 139). Las resoluciones señalan que los magistrados faltaron a la independencia en el ejercicio de la función jurisdiccional, al no haber observado los principios del debido proceso y la tutela jurisdiccional, y haber excluido la motivación escrita de las resoluciones judiciales en las diferentes instancias, como indica la jurisprudencia del Tribunal Constitucional: El derecho a la debida motivación de las resoluciones importa que los jueces, al resolver las causas, expresen las razones o justificaciones objetivas que los llevan a tomar determinada decisión. Esas razones [...] deben provenir no solo del ordenamiento jurídico vigente y aplicable al caso, sino de los propios hechos debidamente acreditados en el trámite del proceso. (Expediente N. ${ }^{\circ}$ 1480-2006-AA/TC, F.J.2.)

- Ley de la Carrera Judicial $N^{\circ}{ }^{\circ}$ 29277. Esta norma es transgredida en un importante número de casos. La destitución de los jueces suele darse por haber infringido sus deberes y por haber cometido faltas graves y muy graves, en el ejercicio de la función jurisdiccional comprendidos en los artículos 34 y 48, respectivamente. Sus sanciones se deben, asimismo, a la falta de motivación en las resoluciones, principio que exige fundamentar o justificar la decisión del juez con hechos debidamente acreditados en el proceso. 
- Ley Orgánica del Ministerio Público (Decreto Legislativo N. ${ }^{\circ}$ 052). Esta norma regula la organización, las atribuciones, las funciones y los fines del Ministerio Público como organismo autónomo del Estado. Los fiscales sancionados con la destitución dejaron de ejercer sus funciones de defensa de la legalidad, defensa de los derechos ciudadanos y los intereses públicos, defensa de la familia, los menores y los incapaces e interés social. Olvidaron cumplir con sus objetivos de velar por la moral pública, la persecución del delito y la reparación civil.

- Reglamento de Organización y Funciones de la Fiscalía Suprema de Control Interno del Ministerio Público. En el caso de los fiscales, las sanciones fueron impuestas por infringir, en su mayoría este Reglamento, que es una herramienta de gestión institucional que comprende un conjunto de principios, normas, órganos y procedimientos destinados a optimizar las funciones que le competen.

- Código de Ética del Ministerio Público. Este instrumento normativo, aprobado por la Resolución de Junta de Fiscales Supremos N. ${ }^{\circ}$ 018-2011-MP-FN-JFS, regula la conducta moral de los fiscales. "Su finalidad es orientar, prevenir y auxiliar al fiscal, ante la interrogante sobre qué hacer frente a la diversidad de situaciones que se presentan en el diario devenir de su vida" (Preámbulo). En efecto, los fiscales, de acuerdo con su ley orgánica, están jerárquicamente organizados y son autónomos en el ejercicio de sus funciones, esto es, aplican un criterio propio con arreglo a la ley y a los fines de su institución. No obstante, si bien este código de ética contiene principios, valores y deberes para todos los fiscales, de los 22 expedientes analizados, solo siete tuvieron como fundamento al Código de Ética del Ministerio Público en la sanción impuesta.

Porúltimo, a la par de la vigencia del Decreto Legislativo $\mathrm{N}^{\circ} 1265$ que crea el RNAS, luego de los graves casos de corrupción conocidos como "Los Cuellos Blancos del Puerto", el 2019 se promulgaron dos leyes de control muy importantes en el sistema de justicia. Se trata de la Ley N. ${ }^{\circ} 30943$, que crea la Autoridad Nacional de Control del Poder Judicial, y la Ley N. ${ }^{\circ} 30944$, que hace lo propio con la Autoridad 
Nacional de Control del Ministerio Público. Para ello, se modificaron diversos artículos de la Ley Orgánica del Poder Judicial, la Ley Orgánica del Ministerio Público y la Ley de la Carrera Fiscal. Estas nuevas instituciones se encargarán del control funcional de los jueces y fiscales en los distintos niveles, así como del personal que labora en el Poder Judicial y el Ministerio Público, con lo cual se busca hacer frente a la corrupción enquistada en el Sistema de Justicia en el país.

\section{Causas y Consecuencias de la Falta de Integridad en la Conducta de Jueces y Fiscales}

Respecto a las causas de la falta de integridad, entendida como la probidad, imparcialidad, equidad, honestidad y veracidad (ONU, 2017) y de la corrupción, definida como: "El mal uso del poder público o privado para obtener un beneficio indebido; económico, no económico o ventaja; directa o indirecta; por agentes públicos, privados o ciudadanos; vulnerando principios y deberes éticos, normas y derechos fundamentales" CAN, 2017, p. 16). Coincidimos con Zeballos, 2019, quien señala que existen una serie de factores que llevan a este tipo de conductas de jueces y fiscales en el país, entre ellos: "temas de accesibilidad, sobrecarga procesal, demora procesal, falta de independencia de los jueces, entre otros". Por otro lado, también está el factor de formación profesional, ocasionada por la proliferación de facultades de Derecho, sobre todo en las universidades con fines de lucro, que ofrecen una deficiente formación profesional y "que, año a año, colocan en el mercado a miles de nuevos profesionales del Derecho con una calificación ciertamente heterogénea, pero, en promedio, ciertamente deficiente" (Albán, 2018). En efecto, las competencias de estos nuevos profesionales son muy cuestionadas y, en la mayoría de los casos, solo giran en torno a conocimientos básicos, puesto que se ha dejado de lado la formación en valores, principios morales y en lo deontológico, los cuales deberían ser incorporados en los programas y planes curriculares de formación del abogado.

La crisis en la formación profesional universitaria dio lugar a la aprobación el año 2014, de una nueva Ley Universitaria N. ${ }^{\circ}$ 30220, la misma que creó la

\section{DERECHO GLOBAL. ESTUDIOS SOBRE DERECHO Y JUSTICIA}


Superintendencia Nacional de Educación Superior Universitaria (SUNEDU), encargada del licenciamiento de las universidades, previa verificación del cumplimiento de las condiciones básicas de calidad en el servicio educativo. Producto de ello, concluido el proceso de licenciamiento, 92 universidades fueron licenciadas y 49 denegadas (Sunedu, 2021). De los cuales, casi la totalidad son privadas y solo tres públicas, las mismas que contaban con un número importante de facultades de Derecho. Mientras tanto, sus promotores incursionaron en la política, con la creación de partidos políticos que llegaron a obtener representatividad en el Congreso, desde donde defienden sus negocios privados, particularmente aquellas creadas bajo el modelo de universidad- empresa, ejerciendo fuerte presión en contra de la SUNEDU y la modificación de la Ley Universitaria.

Y para comprender la profundidad de la crisis, se debe mencionar que una de las consecuencias es que, el Poder Judicial y el Ministerio Público que debería garantizar el ejercicio de los derechos fundamentales, muestra una falta de integridad en la conducta de jueces y fiscales, derivando en actos de corrupción de tipo penal o administrativo, lo que genera un grave problema para el Sistema de Justicia en el Perú. Esta compleja situación de larga data no ha podido ser revertida por ningún gobierno, pese a la aprobación de políticas, planes y reformas impulsadas desde el Estado que no han tenido mayores resultados. Tal es así que la población percibe al Poder Judicial como la más corrupta de las instituciones del país, con los índices de aprobación y de confianza más bajos. Así lo reportan el Instituto Nacional de Estadística e Informática (2020) revela que el 82.3\% de los ciudadanos no confía en el Poder Judicial y que un 73.1\% tampoco confía en el Ministerio Público (p.7). Transparencia Internacional (2019, p.3), organismo que mide la percepción de la ciudadanía, ubica al Perú en el puesto 101 de 180 países del mundo, la ONG Latinobarómetro (2018) también sitúa al Perú como uno de los países de la región con menor índice de confianza (16\%) hacia el Poder Judicial, entidad que "no alcanza a tener la confianza ni de un tercio de la población" (p. 51). 
Otra de las graves consecuencias para el país, es que las estimaciones del costo de la corrupción en los dos últimos siglos redundan en los altos costos que representó la corrupción para el erario nacional; un promedio anual estimado entre el 30\% y $40 \%$ del presupuesto público, y alrededor del 3\% y 4\% de su Producto Bruto Interno (PBI) (Quiroz, 2013). En tanto que para Shack, Pérez \& Portugal, 2020, si se considera que en el año 2019 el PBI del Perú ascendió a 776 miles de millones de soles, el monto de la corrupción bordearía los 15.5 miles de millones de soles; un equivalente al $8 \%$ del presupuesto nacional ejecutado por el gobierno nacional, regional y local (p.16). Todo lo cual no hace más que agravar la situación de pobreza y exclusión de las grandes mayorías, quienes se ven limitados en satisfacer sus necesidades básicas, así como al Estado que ve impedido de atender los servicios de salud, educación, infraestructura, seguridad, entre otros, por la desviación de fondos del presupuesto público a los actos de corrupción.

\section{Conclusiones}

El alto nivel de desprestigio al que habían llegado los hombres de leyes, así como el Sistema de Justicia en el país, hizo que el gobierno de Kuczynski (2016) aprobara una serie de medidas para hacer frente a la corrupción; entre ellas, el Decreto Legislativo No 1265 que crea el Registro Nacional de Abogados Sancionados por Mala Práctica Profesional, dicho Registro entró en vigencia el 2017; desde esa fecha hasta diciembre de 2019 el nivel de abogados sancionados y registrados fue un total de 789, a quienes se les impuso diferentes sanciones administrativas, multa, suspensión, separación y destitución. De los cuales, el tipo de sanción impuesta en mayor porcentaje $(81,24 \%)$ fue la multa, en tanto que solo a un $15,97 \%$ de abogados se le aplicó la destitución. Como se puede inferir de estos datos, la multa constituye una de las medidas más benignas que no refleja el alto número de desaprobación del sistema de justicia, sanción que contribuye muy poco en la lucha contra la corrupción, impidiendo una sanción drástica en casos de transgresión a la ley, única manera de garantizar a la población el derecho a la justicia y revertir los bajos índices de aprobación y de confianza,

\section{DERECHO GLOBAL. ESTUDIOS SOBRE DERECHO Y JUSTICIA}


tal como lo señalan el INEI (2020, p.7), Transparencia Internacional (2019) y Latinobarómetro (2018).

El número de abogados sancionados con la destitución por faltas cometidas en el ejercicio de sus funciones de jueces o fiscales y de acuerdo a su nivel jerárquico, corresponde a los jueces en sus diversos niveles, quienes representan el $71 \%$ del total, en tanto que los fiscales solo el $29 \%$.

De acuerdo al género, los abogados sancionados con la destitución, casi en su totalidad (92\%) corresponde a los varones, puesto que las mujeres solo representan una mínima cantidad del 8\%. En cuanto al lugar, los abogados sancionados en el ejercicio del cargo de jueces y fiscales provienen de la Región Ancash (12), la misma que obtuvo un importante ingreso económico por concepto de canon minero, que constituye el impuesto que pagan al Estado las empresas dedicadas a la actividad minera. Recursos que los gobiernos locales y regionales destinaron al financiamiento de proyectos de inversión pública, a obras de mantenimiento de la infraestructura, entre otros y que dio lugar a flagrantes actos de corrupción de funcionarios que a la fecha se encuentran con sendos procesos judiciales. Le sigue la Región Lima y Lima Metropolitana con 11 destituidos, en este caso se debe a la densidad poblacional de la capital de la República (11 millones de habitantes) que representa una tercera parte de la población de todo el Perú y que cuenta con la mayor cantidad de jueces y fiscales en ejercicio. En tanto que las demás regiones tienen una media de tres jueces o fiscales sancionados.

Los instrumentos normativos que sirvieron de sustento para aplicar las sanciones de destitución corresponden sobre todo a la Ley de la Carrera Judicial, seguida de la Constitución Política del Perú y el Reglamento de Organización y Funciones de la Fiscalía Suprema de Control Interno del Ministerio Público, así como la Ley Orgánica del Poder Judicial.

La implementación del RNAS creado por Decreto Ley Nº 1265 (2016), desde nuestra óptica constituye un gran acierto y logro en la legislación peruana; sin embargo, en 
sus cuatro años de vigencia, es mínimo el impacto que ha tenido en la sociedad y en el ámbito judicial, toda vez que se han ido conociendo un importante número de casos de corrupción en el ámbito del sistema de justica. Su eficacia aún es limitada, entre otros factores por los insuficientes mecanismos de difusión, así como por la falta de un control efectivo en la conducta e integridad de los operadores de justicia que no interiorizan su importancia y las consecuencias que ella trae para la administración de justicia.

Finalmente, el estudio nos lleva a confirmar la hipótesis planteada, que las sanciones impuestas a los jueces y fiscales del Sistema de Justicia en el Perú y registradas en el RNAS, son en su mayoría por faltas consideradas leves como es la multa $(81,24 \%)$, lo que no refleja el alto porcentaje de desaprobación y la falta de confianza, tanto en el Poder Judicial como en el Ministerio Público y que tampoco contribuye a enfrentar el grave problema de la falta de integridad y la corrupción en la conducta de los operadores de justicia.

\section{Recomendaciones}

A fin de reducir los casos de corrupción en el Sistema de Justicia del Perú, que permita a la ciudadanía recobrar la confianza hacia sus instituciones tutelares y el Estado al servicio de la población, se propone que, dado que las normas de control interno, normas de conducta o sobre integridad, así como los códigos de ética del Poder Judicial, Ministerio Público y otras dependencias estatales se encuentran dispersas y sin mayor articulación, desde el ámbito legislativo se debe aprobar una norma o un solo código de ética que sistematice, unifique y actualice las ya existentes, como es el caso de la Ley del Código de Ética de la Función Pública Ley № 27815 de 2002, que establece principios, deberes y prohibiciones éticas, cuya ineficacia en su aplicación ha sido una permanente discusión.

Asimismo, para frenar la corrupción e imponer la cultura de integridad en la conducta de los operadores del derecho, la sanción de destitución debe llevar 
como pena accesoria la cancelación del título profesional de abogado a cargo de los colegios profesionales, que cuentan con sus respectivos tribunales de ética.

Se propone que todos los operadores de justicia, tanto en ejercicio como los que asumen el cargo, especialmente los jueces y fiscales, deberían ser capacitados permanentemente, no solo en materia legal, sino, en aspectos éticos, deontológicos y sobre integridad, a fin de entender que la corrupción constituye uno de los graves problemas que empobrece al país y con nefastas repercusiones económicas, sociales y políticas. Y, tal como propone el Ceriajus, se debe trabajar por una cultura de integridad, a lograr cambios culturales que involucren no solo a los operadores del sistema de justicia, sino a la sociedad civil, de tal forma que "el Sistema de Justicia en su conjunto, debe instituirse como un espacio de lucha contra la impunidad y la corrupción" (p. 75).

Y desde el ámbito educativo, se debe continuar con la moratoria en la creación de nuevas universidades, así como iniciar profundas reformas en la formación profesional universitaria entre ellas la obligatoriedad de la acreditación a todas las Facultades y Escuelas Profesionales de Derecho, que permitan acreditar un gran número de estándares de calidad, entre ellos la revisión de los planes curriculares, el perfil de ingreso y egreso de los futuros abogados, las competencias a lograr, de tal forma que se alcance una mejor formación en valores, principios y en lo deontológico, de quienes irán a ejercer el Derecho, tanto en el ámbito público o privado.

Finalmente, considerando que la corrupción constituye un fenómeno estructural que no solo se da en el ámbito del ejercicio profesional de los abogados, para hacer frente a la falta de integridad en la conducta de los profesionales de las distintas áreas, proponemos aprobar una norma que permita la creación de un registro que involucre y se haga extensivo a todos los colegios profesionales (médicos, ingeniero, economistas, contadores, etc.) y cuyos miembros hayan sido sancionados por mala práctica profesional, de tal forma que se transparente dichas sanciones y la población conozca la conducta de profesionales que sirven a la sociedad. 


\section{Bibliografía}

Albán, W. (2018). Trascendencia y valor de la ética. Jurídica. Suplemento de análisis legal. Recuperado de https://elperuano.pe/ suplementosflipping/juridica/711/web/pagina06.html.

Annan, K. (2004). Prefacio. En Naciones Unidas, Convención de las Naciones Unidas contra la Corrupción (pp. iii-iv). Oficina de las Naciones Unidas contra la Droga y el Delito. Recuperado de https:// www.unodc.org/documents/mexicoandcentralamerica/publications/ Corrupcion/Convencion_de_las_NU_contra_la_Corrupcion.pdf.

Centro Latinoamericano de Administración para el Desarrollo (2018).

Carta Iberoamericana de Ética e Integridad en la Función Pública. Aprobada por la XVIII Conferencia Iberoamericana de Ministras y Ministros de Administración Pública y Reforma del Estado. Antigua. Guatemala, 26 y 27 de julio de 2018. Recuperado de https:// www.dgaep.gov.pt/upload/RI_estudos\%20Presid\%C3\%AAncias/ CartaIberoamericanaEticaeIntegridadFuncionPublica\%20(2).pdf.

Comisión de Alto Nivel Anticorrupción. (2017). Política nacional de integridad y lucha contra la corrupción. Recuperado de https://can. pcm.gob.pe/normas-nacionales/politica-nacional-de-integridad-ylucha-contra-la-corrupcion/

Comisión Especial para la Reforma Integral de la Administración de Justicia (2004). Plan Nacional para la Reforma Integral de la Administración de Justicia. Recuperado de http://www4.congreso. gob.pe/comisiones/2004/ceriajus/Plan_Nacional_ceriajus.pdf.

Convención de las Naciones Unidas contra la Corrupción (2004). Oficina de las Naciones Unidas contra la Droga y el Delito. Recuperado de https://www.unodc.org/documents/ mexicoandcentralamerica/publications/Corrupcion/Convencion_ de_las_NU_contra_la_Corrupcion.pdf.

\section{DERECHO GLOBAL. ESTUDIOS SOBRE DERECHO Y JUSTICIA}


Convención Interamericana contra la Corrupción (1996). Recuperado de http://www.oas.org/es/sla/ddi/docs/tratados multilaterales_interamericanos_B-58_contra_Corrupcion.pdf. Giusti, M. \& Tubino, F. (Eds.) (2010). Debates de la ética contemporánea. Lima: Fondo Editorial de la Pontificia Universidad Católica del Perú. Instituto Nacional de Estadística e Informática (2020). Informe técnico.

Perú: percepción ciudadana sobre gobernabilidad, democracia y confianza en las instituciones. Octubre 2019-marzo 2020. Recuperado de https:/www1.inei.gob.pe/media/MenuRecursivo/ boletines/informe_de_gobernabilidad_may2020.pdf.

Klitgaard, R. (1998). La cooperación internacional contra la corrupción.

Finance \& Development, 3-6. Recuperado de https://1997-2001. state.gov/global/narcotics_law/global_forum/F600espaocr.pdf.

Huaita, M., Chanjan, R., \& Saravia, M. (2019). Género y corrupción. Una mirada a los impactos diferenciados de la corrupción en el Perú, Informe final. Lima: Instituto de Democracia y Derechos Humanos de la Pontificia Universidad Católica del Perú. https://cdn01. pucp.education/idehpucp/wp-content/uploads/2019/12/22175921/ G\%C3\%A9nero-y-corrupci\%C3\%B3n-r_.pdf

Huaita, M. (2018). Análisis de la Encuesta anticorrupción de Proética 2017, desde una perspectiva de género. Informe de consultoría. Lima: Proética

Latinobarómetro (2018). Informe 2018. http://www.rendircuentas. org/wp-content/uploads/2019/04/INFORME_2018_ LATINOBAROMETRO.pdf.

Malem, J. (2014). La corrupción. Algunas consideraciones conceptuales. Illes Imperis, (16), 169-178. Recuperado de https://www.raco.cat/ index.php/IllesImperis/article/view/284890/381859.

Martínez, E. (2002). Filosofía del Derecho. México: Cárdenas Editor y Distribuidor. 
Ministerio de Justicia y Derechos Humanos (2016). Constitución Política del Perú. Sistema Peruano de Información Jurídica. Recuperado de http://spij.minjus.gob.pe/content/publicaciones_oficiales/img/ Const-peru-oficial.pdf.

Ministerio de la Mujer y Poblaciones Vulnerables ((2017). X Informe de avances en el cumplimento de la Ley de Igualdad de Oportunidades entre Mujeres y Hombres. Ley $N^{\circ}$ 28983. https://cdn.www.gob.pe/ uploads/document/file/204459/X_INFORME_LIO_.pdf

Ministerio Público. Fiscalía de la Nación (2016). Código de Ética del Ministerio Público. Recuperado de https://fiscalia.gob.pe/Docs/0/ files/codigo_de_etica.pdf.

Ministerio Público. Fiscalía de la Nación (2005). Reglamento de Control Interno. Recuperado de http:/www.oas.org/juridico/PDFs/ mesicic5_per_41_res_005_2004_MP_FN_JFS.pdf.

Mujica, J. (2011). Actores y escenarios de los sistemas de microcorrupción en el Palacio de Justicia del centro de Lima, Perú. Relaciones. Estudios de Historia y Sociedad, 32(126), 87-117. Recuperado de http://www.scielo.org.mx/pdf/rz/v32n126/v32n126a4.pdf.

Naciones Unidas (2017). Estatuto y Reglamento del Personal de las Naciones Unidas. Boletín del Secretario General. https:// digitallibrary.un.org/record/855429/files/ST_SGB_2017_1-ES.pdf.

Naciones Unidas para el Desarrollo (2013). Informe Regional de Desarrollo Humano 2013-2014. Seguridad ciudadana con rostro humano: diagnóstico y propuestas para América Latina. Recuperado de $h \mathrm{ttps}: / /$ www.undp.org/content/dam/rblac/img/IDH/IDH-AL\%20 Informe\%20completo.pdf

Organización para la Cooperación y el Desarrollo Económicos (2017). Estudios de la OCDE sobre integridad en el Perú. Reforzar la integridad del sector público para un crecimiento incluyente. Estudios de la OCDE sobre Gobernanza Pública. Éditions OCDE. Recuperado de http://dx.doi.org/10.1787/9789264271470-es. 
Palomino, C. (2018). Acerca del Registro de Abogados Sancionados por Malas Prácticas Profesionales. Recuperado de https://es.scribd.com/ document/338663258/ACERCA-DEL-REGISTRO-NACIONALDE-ABOGADOS-SANCIONADOS-POR-MALA-PRACTICAPROFESIONAL.

Pásara, L. (2016). 45 años de cambios sin mejora. Revista del Instituto de Defensa Legal, (257). Recuperado de https://revistaideele.com/ ideele/content $/ 45$-a\%c3\%b1os-de-cambios-sin-mejora.

Pérez, C. (2005). Muestreo estadístico. Madrid: Pearson Prentice Hall. Pérez, M. (2007). Ética y deontología para profesionales de la biblioteconomía y documentación. Recuperado de http://eprints. rclis.org/19144/1/Margarita.pdf.

Piana, R. \& Arévalo, M. (2018). La corrupción y el control judicial en Argentina. Su estudio a partir de los fallos de Emir Fuad Yoma, María Julia Alsogaray y Cristobal Lopez. Revista Digital Constituição e Garantia de Direitos, 11(2), 136-154. Recuperado de https://periodicos. ufrn.br/constituicaoegarantiadedireitos/article/view/15960/11376.

Proyecto de Ley N. ${ }^{\circ}$ 3164/2018-PE. Ley para Incentivar la Probidad en el Ejercicio de la Abogacía. 1 agosto 2018. Recuperado de https://www. minjus.gob.pe/wp-content/uploads/2018/08/PL_3164_20180802_ INCENTIVAR-LA-PROBIDAD-EN-EL-EJERCICIO-DE-LAABOGACIA.pdf

Quiñonez, D. (2016). Corrupción y estudios de abogados de Lima. Una relación no excluyente. Revista del Instituto de Defensa Legal, (267). https://revistaideele.com/ideele/content/corrupci\%C3\%B3n-yestudios-de-abogados-de-lima-una-relaci\%C3\%B3n-no-excluyente. Quiñonez, D. (2018). Etnografia de la corrupción en estudios de abogados de Lima. [Tesis de maestría inédita]. Universidad Nacional Mayor de San Marcos. Recuperado de https://cybertesis.unmsm. edu.pe/bitstream/handle/20.500.12672/9060/Qui\%c3\%b1ones_ oh.pdf? sequence $=1 \&$ isAllowed $=\mathrm{y}$. 
Quiroz, A. (2013). Historia de la corrupción en el Perú. Lima: Instituto de Estudios Peruanos.

Ramírez, V. (2012). Consideraciones jurídicas sobre la ética y la moral de los profesionales en Derecho. [Tesis de licenciatura inédita]. Universidad de Costa Rica. Recuperado de http://iij.ucr.ac.cr/ wp-content/uploads/bsk-pdf-manager/2017/08/TESIS-FINALIMPRIMIR.pdf.

Sabsay, D. (2004). El juicio político a la Corte Suprema en la República Argentina. Anuario Iberoamericano de Justicia Constitucional, (8), 493-519. Recuperado de https://recyt.fecyt.es/index.php/AIJC/ article/view/50728/30951.

Sanromán, R.; González, I. \& Villa, M. (2015). Los principios éticos y las obligaciones civiles. Boletín Mexicano de Derecho Comparado, 48(142), 313-338. Recuperado de http://www.scielo.org.mx/pdf/ bmdc/v48n142/v48n142a9.pdf.

Shack, N., Pérez, J., \& Portugal, L. (2020). Cálculo del tamaño de la corrupción y la inconducta funcional en el Perú: Una aproximación exploratoria. Documento de Política en Control Gubernamental. Contraloría General de la República. Lima, Perú. https://doc. contraloria.gob.pe/estudios-especiales/documento_trabajo/2020/ Calculo_de_la_Corrupcion_en_el_Peru.pdf

Spittler, M. (2012). La lucha anticorrupción desde la Fiscalía de la Corte Penal Internacional. En H. Pease \& G. Peirano (Eds.), V Seminario de Reforma del Estado. La lucha anticorrupción como política de Estado (pp. 21-39). Fondo Editorial de la Pontificia Universidad Católica del Perú.

Superintendencia Nacional de Educación Superior Universitaria (2021). Universidades con licencia denegada. https://www.sunedu.gob.pe/ lista-de-universidades-denegadas/

Transparency Internacional (2019). Índice de percepción de la corrupción. Recuperado de https://www.proetica.org.pe/wp-content/ uploads/2020/01/CPI2019_Report_ES-WEB.pdf 
Zeballos, V. (2019). Decisión y compromiso por una justicia transparente y más cercana al ciudadano. Importancia de la reforma judicial. Jurídica. Suplemento de análisis legal. Recuperado de https:// elperuano.pe/suplementosflipping/juridica/711/web/pagina03.html.

\section{JURISPRUDENCIA}

Tribunal Constitucional. Sentencia N. ${ }^{\circ}$ 0023-2003-AI/TC, 9 junio 2004. Recuperado de https://www.tc.gob.pe/jurisprudencia/2004/000232003-AI.pdf.

Tribunal Constitucional. Sentencia N. ${ }^{\circ}$ 01480-2006-AA/TC, 27 marzo 2006. Recuperado de https://tc.gob.pe/jurisprudencia/2007/014802006-AA.pdf.

\section{LEGISLACIÓN}

Decreto Legislativo $N^{\circ}$. 052/1981, de 16 de marzo, por el cual se aprueba la Ley Orgánica del Ministerio Público. Recuperado de https:// cdn.www.gob.pe/uploads/document/file/1115895/ley_organica_ ministerio_publico.pdf.

Decreto Legislativo $\mathrm{N}^{\circ} .1265 / 2016$, de 15 de diciembre, que crea el Registro Nacional de Abogados Sancionados por Mala Práctica Profesional. Diario Oficial "El Peruano", Recuperado de http://spij.minjus.gob.pe/ content/noticia/pdf/DECRETO-LEGISLATIVON1265.pdf.

Decreto Supremo N . 002-2017-JUS/2017, de 27 de enero, que aprueba el Reglamento del Decreto Legislativo No 1265 , Decreto Legislativo que crea el Registro Nacional de Abogados Sancionados por Mala Práctica Profesional. Diario Oficial "El Peruano”, Recuperado de https://busquedas.elperuano.pe/download/url/decreto-supremo-queaprueba-el-reglamento-del-decreto-legisl-decreto-supremo-n-0022017-jus-1479011-1. 
Decreto Supremo No. 092-2017-PCM/2017, de 14 de setiembre, que aprueba la Política Nacional de Integridad y Lucha contra la Corrupción. Diario Oficial "El Peruano", Recuperado de https:// busquedas.elperuano.pe/download/url/decreto-supremo-queaprueba-la-politica-nacional-de-integrid-decreto-supremo-n-0922017-pcm-1565307-1.

Decreto Supremo No. 044-2018-PCM/2018, de 26 de abril de 2018, que aprueba el Plan Nacional de Integridad y Lucha contra la Corrupción 2018-2021. Diario Oficial “El Peruano”, Recuperado de https://busquedas.elperuano.pe/download/url/decreto-supremo-queaprueba-el-plan-nacional-de-integridad-y-decreto-supremo-n-0442018-pcm-1641357-2.

Decreto Supremo Nº. 042-2018-PCM/2018, de 22 de abril, que establece medidas para fortalecer la integridad pública y lucha contra la corrupción. Diario Oficial "El Peruano", Recuperado de https:// busquedas.elperuano.pe/download/url/decreto-supremo-queestablece-medidas-para-fortalecer-la-int-decreto-supremo-n-0422018-pcm-1639860-1.

Ley N ${ }^{\circ} .27815 / 2002$, de 13 de agosto, aprueba la Ley del Código de Ética de la Función Pública. Diario Oficial "El Peruano", Recuperado de http:/www4.congreso.gob.pe/historico/cip/temas/descentralizacion/ pdf/09A01.pdf.

Ley N ${ }^{\circ}$. 29277/2008, de 7 de noviembre, por medio del cual se expide la Ley de la Carrera Judicial. Diario Oficial "El Peruano", Recuperado de https://leyes.congreso.gob.pe/Documentos/Leyes/29277.pdf.

Ley $N^{\circ}$. 29976/2013, de 4 de enero, por la cual se aprueba la Ley que crea la Comisión de Alto Nivel Anticorrupción. Diario Oficial "El Peruano", Recuperado de https://leyes.congreso.gob.pe/ Documentos/Leyes/29976.pdf. 
Ley $\mathrm{N}^{\circ}$. 30220/2014 de 9 de junio, por la que se aprueba la Ley Universitaria. Diario Oficial "El Peruano", Recuperado de https:// leyes.congreso.gob.pe/Documentos/Leyes/30220.pdf.

Ley $\mathrm{N}^{\circ}$. 30943/2019 de 8 de mayo, mediante la cual se aprueba la Ley de Creación de la Autoridad Nacional de Control del Poder Judicial. Diario Oficial "El Peruano", Recuperado de https://busquedas. elperuano.pe/download/url/ley-de-creacion-de-la-autoridadnacional-de-control-del-pode-ley-n-30943-1767288-2.

Ley $\mathrm{N}^{\circ}$. 30944/2019, de 8 de mayo, mediante la cual se aprueba la Ley de Creación de la Autoridad Nacional de Control del Ministerio Público. Diario Oficial "El Peruano", Recuperado de https:// busquedas.elperuano.pe/download/url/ley-de-creacion-de-laautoridad-nacional-de-control-del-mini-ley-n-30944-1767288-3.

Resolución de Junta de Fiscales Supremos No. 003-2018-MP-FNJFS/2018, de 31 de enero, mediante el cual, Modifican el Reglamento de Organización y Funciones de la Fiscalía Suprema de Control Interno. Diario Oficial "El Peruano", Recuperado de https:// busquedas.elperuano.pe/download/url/modifican-el-reglamento-deorganizacion-y-funciones-de-la-fi-resolucion-n-003-2018-mp-fnjfs-1611855-1. 